\title{
西双版纳热带季节雨林与橡胶林土壤呼吸
}

\author{
房秋兰 1,2 沙丽清 $1 *$ \\ （1 中国科学院西双版纳热带植物园昆明分部, 昆明 650223）（2 中国科学院研究生院, 北京 100039）
}

\begin{abstract}
摘 要 季节雨林和橡胶 (Hevea brasiliensis) 林是西双版纳热带森林生态系统中原始林和大面积种植人工林的两种 代表类型。热带季节雨林层次结构复杂, 多样性丰富, 而橡胶林结构简单, 乔木层只有橡胶树 1 种。应用碱吸收 法, 研究了这两种植被类型土壤呼吸速率、地下 $5 \mathrm{~cm}$ 土壤温度、气温和土壤含水率的季节变化规律, 以及土壤呼吸 速率与地下 $5 \mathrm{~cm}$ 土壤温度、气温和土壤含水率的关系。结果表明: 1) 季节雨林和橡胶林土壤呼吸速率、土壤温度、 气温和土壤含水率都有明显的季节变化, 而且两种林型的变化趋势基本一致; 2)季节雨林和橡胶林土壤呼吸速率 与地下 $5 \mathrm{~cm}$ 土壤温度和气温之间具有显著的指数相关关系, 显著水平达 $1 \%$, 与地下 $5 \mathrm{~cm}$ 温度的相关性 $\left(r^{2}\right.$ 分别为 0.87 和 0.82 ) 明显高于与气温的相关性 ( $r^{2}$ 分别是 0.80 和 0.72$) ; 3$ ) 季节雨林和橡胶林土壤呼吸速率与土壤含水率 具有显著的线性相关 $\left(r^{2}\right.$ 分别是 0.73 和 0.63$)$, 显著水平达 $1 \% ; 4$ ) 橡胶林的土壤呼吸速率明显高于季节雨林, 这与 两种林型的结构有关; 5) 季节雨林和橡胶林土壤呼吸的 $Q_{10}$ 分别为 2.16 和 2.18, 比文献报道的热带土壤的 $Q_{10}$ (1.96)稍高。
\end{abstract}

关键词 西双版纳 季节雨林 橡胶林 土壤呼吸速率 $Q_{10}$

\section{SOIL RESPIRATION IN A TROPICAL SEASONAL RAIN FOREST AND RUBBER PLANTATION IN XISHUANGBANNA, YUNNAN, SW CHINA}

\author{
FANG Qiu-Lan ${ }^{1,2}$ and SHA Li-Qing ${ }^{1 *}$ \\ (1 Xishuangbanna Tropical Botanical Garden, Chinese Academy of Sciences, Kunming 650223, China) \\ (2 Graduate School of Chinese Academy of Sciences, Beijing 100039, China)
}

\begin{abstract}
Xishuangbanna is the most northerly situated tropical rain forest in the world and, as a result, has remarkable seasonal climate variations, which is different from tropical rain forests in other regions. In Xishuangbanna, the canopy of rubber plantations, Hevea brasiliensis, often form a single layer structure that is different from the multi-layer canopy of tropical seasonal rain forests. The objectives of this study were as the following: 1) to compare the soil respiration characteristics of a rubber plantation and a natural tropical seasonal rainforest using the alkaline absorption technique; 2) to measure seasonal changes in air temperature, soil temperature at $5 \mathrm{~cm}$ depth, soil water content and soil respiration rates in two communities; and 3) to evaluate the relationships between soil respiration rates and soil temperature, air temperature, and soil water content.

Measurements of soil respiration rates were carried out for one year in a tropical seasonal rain forest in a Nature Reserve $\left(21^{\circ} 57^{\prime} \mathrm{N}, 101^{\circ} 12^{\prime} \mathrm{E}\right)$ and a rubber plantation $\left(21^{\circ} 56^{\prime} \mathrm{N}, 101^{\circ} 15^{\prime} \mathrm{E}\right)$. The two sites are about $5 \mathrm{~km}$ away near the Xishuangbanna Tropical Botanical Garden in Xishuangbanna, Yunnan.

The results showed that there was remarkable seasonal changes in the soil respiration rates in both the tropical seasonal rain forest and rubber plantation with changes in soil temperature at $5 \mathrm{~cm}$ depth, air temperature and soil water content. Soil respiration rates of the tropical seasonal rain forest and rubber plantation were greatest in October $\left(9.24\right.$ and $11.06 \mathrm{~kg} \mathrm{CO} \cdot \mathrm{m}^{-2} \cdot \mathrm{d}^{-1}$, respectively), and lowest in February (4.71 and $5.13 \mathrm{~kg} \mathrm{CO}{ }_{2} \cdot \mathrm{m}^{-2} \cdot \mathrm{d}^{-1}$, respectively). Soil respiration rates in May, June, July, August, September and October were higher than those in November, December, January, February, March and April. Soil respiration rates in the rubber plantation were significantly higher than that of the tropical seasonal rain forest $(p<$ $0.01)$. There was a significant correlation between soil respiration rates and soil temperature at $5 \mathrm{~cm}$ depth, air temperature, and the correlation between soil respiration rate and soil temperature $\left(r^{2}=0.87\right.$ and $r^{2}=$ 0.82 , respectively $)$ was higher than that between soil respiration rate and air temperature $\left(r^{2}=0.80\right.$ and $r^{2}=$ 0.72 , respectively $)(p<0.01)$ for the forest and plantation. There was a significant $(p<0.01)$ correlation
\end{abstract}


between soil respiration rates and soil water content in the forest and plantation $\left(r^{2}=0.73\right.$ and $r^{2}=0.63$, respectively). The annual $\mathrm{CO}_{2}$ efflux from the tropical seasonal rain forest and rubber plantation were 2.64 and $2.80 \mathrm{~kg} \mathrm{CO}{ }_{2} \cdot \mathrm{m}^{-2} \cdot \mathrm{a}^{-1}$, respectively. The $Q_{10}$ values of the tropical seasonal rain forest and rubber plantation were 2.16 and 2.18, respectively. The $Q_{10}$ value of the tropical seasonal rain forest measured by the alkaline absorption method in our study was slightly higher than values measured using the static opaque chamber and gas chromatography techniques. The $Q_{10}$ values of the seasonal tropical rain forest and rubber plantation in Xishuangbanna are higher than those reported in other tropical regions.

Key words Xishuangbanna, Tropical seasonal rain forest, Rubber (Hevea brasiliensis) plantation, Soil respiration, $Q_{10}$

碳 $(\mathrm{C})$ 元素是陆地表层生命有机体的关键组成 部分, 是参与陆地生物地球化学循环最活跃的元素 之一。碳循环是生物圈健康发展的重要标志 (Gupta \& Singh, 1981)。土壤呼吸是土壤释放 $\mathrm{CO}_{2}$ 的过程, 是陆地生态系统碳循环的一个重要组成部分, 也是 土壤碳库主要输出途径。全球土壤是一个巨大的 $\mathrm{C}$ 库 $\left(1.394 \times 10^{18} \mathrm{~g}\right)$, 是大气 $\mathrm{CO}_{2}$ 的重要来源 $($ Jenkinson et al., 1991), 土壤 C 库的微小变化都可能导致 大气 $\mathrm{CO}_{2}$ 浓度的显著变化 (王沝等, 2003; 刘绍辉 等, 1998)。据估计, 全球每年排放 C 量高达 $68 \times$ $10^{15} \mathrm{~g}^{\circ} \mathrm{a}^{-1}$ 。由于大气 $\mathrm{CO}_{2}$ 是引起全球变化的重要 温室气体 (Jenkinson et al ., 1991), 因此准确评估土 壤呼吸作用及其对全球变化的响应具有十分重要的 意义。

影响土壤 $\mathrm{CO}_{2}$ 释放的因子有许多, 如土壤温度、 土壤含水率、土壤容重、孔隙度、 $\mathrm{pH}$ 值以及重金属离 子等, 其中最主要的是土壤温度和土壤含水率 (Krischbaum, 1995; Kucera \& Kirlcham, 1971; Moore \& Dalva, 1993; Moore \& Knowles, 1989; Wildung et $a l ., 1975)$ 。国外不少研究已经证实土壤呼吸与土 壤温度呈正相关 (Mathes \& Schriefer, 1985; Moore \& Knowles, 1989; 王秋等, 2003)。国内的不少学者也 做了相应的研究报道, 如东北羊草 (Leymus chinensis) 草原(杨靖春等，1989)、长白山温带森林(王永等, 2003)、北京山地温带森林(刘绍辉和方精云，1997; 刘绍辉等, 1998; 蒋高明和黄银晓, 1997)、中亚热 带东部林区(黄承才等，1999)、尖峰岭热带森林 (吴 仲民等，1997), 但我国西双版纳热带森林土壤呼吸 方面的研究少见报道。

西双版纳的热带雨林是分布在热带北缘水热和 海拔高度极限条件下的森林类型, 具有热带森林的 结构和群落特征, 但在种类组成上又有向南亚热带 森林过渡的特点, 与赤道湿润雨林有所不同 (朱华, 1999)。橡胶 (Hevea brasiliensis) 林是西双版纳地区大 面积分布的人工林, 从 20 世纪 60 年代初期开始, 由
于对天然橡胶的迫切需要, 我国在西双版纳地区进 行了大规模的橡胶林种植工作。本区的气候、土壤、 水分条件十分适合橡胶林生长, 产胶量不但高于我 国海南岛, 在世界范围内也比较高, 因此在西双版纳 种植面积较大, 占有林地面积的 $25.9 \%$ (江爱良, 1987), 近年来随着山地承包到户, 橡胶的种植面积 又进一步增加。据统计年鉴, 西双版纳土地总面积 为 $177.9 \times 10^{4} \mathrm{hm}^{2}$, 耕地面积为 $11.48 \times 10^{4} \mathrm{hm}^{2}$, 占总 面积的 $6 \%$, 水田面积为 $4.269 \times 10^{4} \mathrm{hm}^{2}$, 占耕地总 面积的 $37.2 \%$, 橡胶林面积为 $13.62 \times 10^{4} \mathrm{hm}^{2}$, 是水 田的 3 倍多(云南省统计局, 1998)。

季节雨林和橡胶林是西双版纳热带森林生态系 统中原始林和大面积种植的人工林两种代表类型, 在当地森林中占有很大的比重, 作为土壤 $\mathrm{C}$ 库在释 放 $\mathrm{CO}_{2}$ 方面也有重要作用。热带季节雨林多层多 种, 结构复杂; 橡胶林单层单种, 结构简单。在同一 地区内, 这两种差异较大的林型同时存在, 其土壤呼 吸释放有何异同? 值得探讨。同时为了揭示西双版 纳地区两种不同林型的土壤呼吸速率与温度和水分 的相关性, 本文对这两种不同类型的土壤呼吸特征 进行了初步研究。

\section{1 研究区概况及林分特征}

西双版纳终年受西南季风控制, 属热带季风气 候,一年中有雾凉季 (11 月～翌年 2 月)、干热季 (3 $\sim 4$ 月) 和湿热季 ( $5 \sim 10$ 月)之分。年平均气温 21.5 ${ }^{\circ} \mathrm{C}, \geqslant 10{ }^{\circ} \mathrm{C}$ 积温 $7860{ }^{\circ} \mathrm{C}$, 平均最低气温 $7.5{ }^{\circ} \mathrm{C}$, 年 日照时数 $1828 \mathrm{~h}$, 年降水量 $1557 \mathrm{~mm}$, 年相对湿度 $86 \%$, 干燥度 1.01 , 年径流量 $764 \mathrm{~mm}$ 。土壤为由白 严纪砂岩发育而成的砖红壤。

季节雨林样地位于云南省西双版纳州预腊县预 仑镇的国家级自然保护区内 $\left(21^{\circ} 57^{\prime} \mathrm{N}, 101^{\circ} 12^{\prime} \mathrm{E}\right.$, 海 拔 $756 \mathrm{~m}$ ), 群落高度 $40 \mathrm{~m}$ 左右, 结构复杂, 分层现象 明显, 乔木层按高度可分为 3 层: 上层高 $30 \mathrm{~m}$ 以上, 标志种主要为千果榄仁 ( Terminalia myriocarpa)、番 
龙眼 ( Pometia tomentosa); 中层高度在 $16 \sim 30 \mathrm{~m}$ 之 间, 常见种有云南玉芯 (Barringtonia macrostachya)、 大叶白颜树 (Gironniera subaequalis) 等; 下层高 $16 \mathrm{~m}$ 以下, 主要种包括云树 ( Garcinia cowa)、假广子( Knema erratica)、细罗伞 (Ardisia tenera)、蚁花 (Mezzettiopsis creaghii) 及毒鼠子( Dichapetalum gelonioides) 等。 灌木层除上层乔木的幼苗幼树外, 常见种有染木 ( Saprosma ternatum)、狭叶巴戟 (Morinda angustifoli$a$ )、玉叶金花 (Mussaenda sp.) 等。草本层与灌木层 处于同一层次, 种类不多, 常见种有海芋 (Alocasia mocrorrhiza)、凤尾蕨 (Pteris sp.) 等。藤本及附生植 物丰富, 板根及茎花现象显著, 是典型的季节雨林 (任泳红等，1999）。

橡胶林样地设在中国科学院西双版纳热带森林 生态系统研究站的人工群落试验区内 $\left(21^{\circ} 56^{\prime} \mathrm{N}\right.$, $101^{\circ} 15^{\prime} \mathrm{E}$, 海拔 $580 \mathrm{~m}$ ), 是以 20 年生橡胶林为主的 单优人工群落, 采用宽窄行密株的种植方式(株距 $3.1 \mathrm{~m}$, 窄行距 $2.5 \mathrm{~m}$, 宽行距 $19.0 \mathrm{~m}$ ), 群落高 $20 \sim$ $30 \mathrm{~m}$, 乔木层数目密度 370 株 $\cdot \mathrm{hm}^{-2}$ 。土壤为砖红 壤, 土层深厚, 坡度约为 $15^{\circ}$ 。

\section{2 研究方法}

\section{1 土壤呼吸的测定}

在季节雨林和橡胶林分别选取 3 块样地, 从 2003 年 9 月至 2004 年 9 月, 每个月的 9、10 日在每 块样地内随机选取 4 个点做土壤呼吸试验。测定土 壤呼吸的方法为碱溶液密闭吸收法, 测定所用的密 闭容器是用马口铁皮卷制的直径 $16 \mathrm{~cm}$ 、高 $20 \mathrm{~cm}$ 的 圆形筒, 在每个倒置的铁筒下放置一个盛 $20 \mathrm{ml} 1$ $\mathrm{mol} \cdot \mathrm{L}^{-1} \mathrm{NaOH}$ 溶液的塑料广口瓶, 广口瓶敞口放 置, 把圆形筒插入土壤 $10 \mathrm{~mm}$; 同时, 每个样地随机 放置 2 个盛 $20 \mathrm{ml} 1 \mathrm{~mol} \cdot \mathrm{L}^{-1} \mathrm{NaOH}$ 溶液的塑料广口 瓶，盖着盖子放在铁筒下, 在实验开始和结束时将其 打开暴露在空气中, 用作对照以减少误差。 $24 \mathrm{~h}$ 后 从铁筒下取出所有的广口瓶, 盖上盖带回实验室。 从塑料瓶中量取 $5 \mathrm{ml} \mathrm{NaOH}$ 溶液加入 $2.5 \mathrm{ml}$ 的 1 $\mathrm{mol} \cdot \mathrm{L}^{-1} \mathrm{BaCl}_{2}$ 溶液生成 $\mathrm{BaCO}_{3}$ 沉淀, 再用 $1 \mathrm{~mol} \cdot \mathrm{L}^{-1}$ $\mathrm{HCl}$ 滴定到酚酞终点, 然后计算 $\mathrm{CO}_{2}$ 量。

碱吸收法的土壤呼吸速率用下面的公式计算:

$$
\mathrm{CO}_{2}\left(\mathrm{~g} \cdot \mathrm{m}^{-2} \cdot \mathrm{d}^{-1}\right)=44\left(V_{1}-V_{2}\right) N / 1000 A T
$$

式中: $V_{1}$ 为滴定对照 $\mathrm{NaOH}$ 溶液所用的 $\mathrm{HCl}$ 溶液体 积; $V_{2}$ 为滴定处理中未与 $\mathrm{CO}_{2}$ 反应的 $\mathrm{NaOH}$ 溶液所 用的 $\mathrm{HCl}$ 溶液的体积; $N$ 为 $\mathrm{HCl}$ 物质的量浓度; $A$ 为 筒的底面积; $T$ 为培养时间。

\section{2 土壤理化性质的测定}

在季节雨林和橡胶林试验样地内各取 5 份土样 风干保存, 进行土壤理化性质分析 (表 1)。每次作 土壤呼吸试验的同时, 用环刀在距离每个测定土壤 呼吸的点 $10 \mathrm{~cm}$ 处取 1 份土样 $(0 \sim 10 \mathrm{~cm})$ 装在自封 袋中,一共 12 份, 带回实验室测定土壤含水率。

2.3 温度的测定

气温和 $5 \mathrm{~cm}$ 土壤温度是测定土壤呼吸的当天 日平均值。

表 1 热带季节雨林和橡胶林土壤理化性质

Table 1 Physical and chemical properties of soil in tropical seasonal rain forest and rubber plantation

\begin{tabular}{lcccc}
\hline \multicolumn{1}{c}{$\begin{array}{c}\text { 群 落 } \\
\text { Community }\end{array}$} & $\mathrm{pH}$ & $\begin{array}{c}\text { 土壤有机质 } \\
\text { Organic } \\
\text { matter } \\
\left(\mathrm{g} \bullet \mathrm{kg}^{-1}\right)\end{array}$ & $\begin{array}{c}\text { 土壤有效氮 } \\
\text { Available } \\
\text { nitrogen } \\
\left(\mathrm{mg} \bullet \mathrm{kg}^{-1}\right)\end{array}$ & $\begin{array}{c}\text { 土壤有效磷 } \\
\text { Available } \\
\text { phosphorus } \\
\left(\mathrm{mg} \bullet \mathrm{kg}^{-1}\right)\end{array}$ \\
$\begin{array}{l}\text { 热带季节雨林 } \\
\begin{array}{l}\text { Tropical seasonal } \\
\text { rain forest } \\
\text { 橡胶林 }\end{array}\end{array}$ & 4.5 & 32.2 & 165.2 & 2.51 \\
$\begin{array}{l}\text { Rubber } \\
\text { plantation }\end{array}$ & 4.9 & 28.0 & 165.0 & 6.1 \\
\hline
\end{tabular}

\section{3 结果与分析}

\section{1 两种群落土壤呼吸的特点}

季节雨林和橡胶林土壤呼吸速率 (去除调落物 层的土壤)都是随着季节变化呈现规律性的变化, 变 化的趋势基本一致, 只是变化的幅度有所不同。无 论是季节雨林还是橡胶林, 土壤呼吸速率均为 5 10 月大于 11 月～翌年 4 月,与地下 $5 \mathrm{~cm}$ 温度、气 温、土壤含水率的季节变化相一致(图 1)。11 月雾 凉季来临, 温度开始下降, 土壤含水率减小, 土壤呼 吸减弱, 到 2 月达到最低; 3 月干热季来临, 温度有 所回升, 但是降水比较少, 土壤含水率小, 土壤呼吸 出现微小波动, 随着雨季的到来, 5 月土壤呼吸开始 增大。总的来看, 土壤呼吸速率与气温和土壤 $5 \mathrm{~cm}$ 温度以及土壤含水率均呈现出较好的耦合规律。

本研究中所选取的两种林分的结构差异比较 大, 季节雨林结构复杂, 层次较多, 林分郁闭较好, 丰 富的藤本及附生植物使各层次之间、林分之间的界 限更加模糊; 而橡胶林为人工群落, 结构整齐, 层次 简单分明。从两种群落土壤呼吸速率及各环境因子 比较看, 无论是土壤呼吸强度、气温、土温、土壤含水 率都是橡胶林 $>$ 季节雨林 $(p<0.01)$, 由此可以看 出土壤呼吸速率的主要影响因子是温度和土壤含 


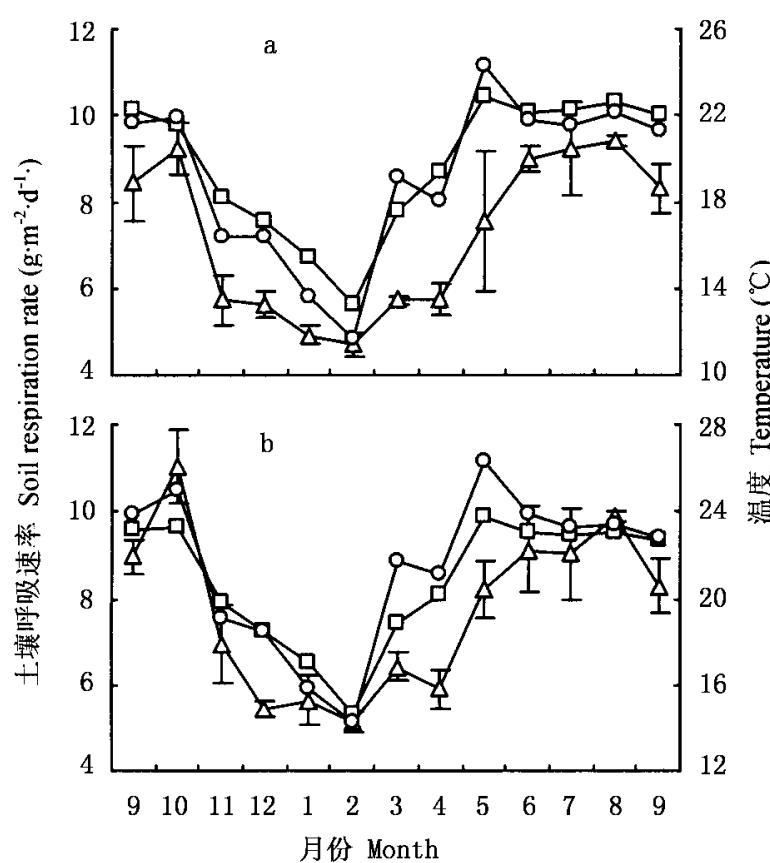

口: 上温 Soil temperature at $5 \mathrm{~cm}$ depth $\triangle:$ 土壤呼吸速率 Soil respiration rate

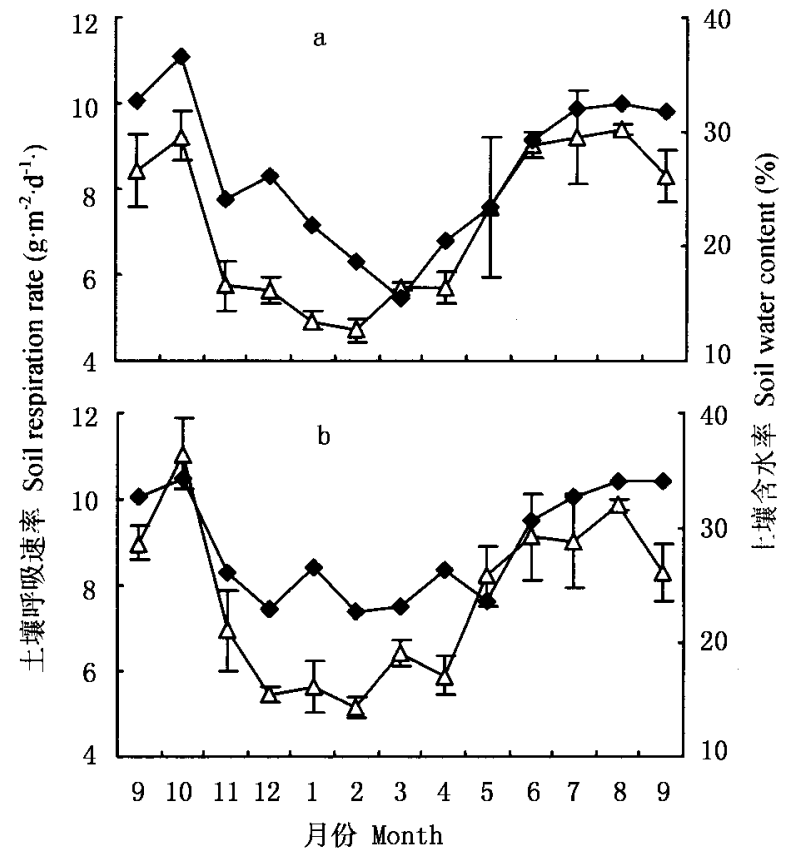

o: 气温 Air temperature

: 七壤含水率 Soil water content

图 1 季节雨林 $(\mathrm{a})$ 、橡胶林 $(\mathrm{b})$ 气温、土温、土壤含水率与土壤呼吸速率的季节变化

Fig. 1 Seasonal changes in air temperature, soil temperature at $5 \mathrm{~cm}$ depth, soil water content and soil respiration rate in two communities, tropical seasonal rain forest $(\mathrm{a})$ and rubber plantation $(\mathrm{b}$ )

图中土壤呼吸数据为 12 个重复的平均值 \pm 标准误差 The data were the mean \pm standard error of 12 separate measurements

水率。橡胶林是人工林, 结构简单, 林型比较单一, 得到的光照比较多, 土壤温度比季节雨林高 $1 \sim 3$ ${ }^{\circ} \mathrm{C}$; 再加上人为的施肥使得林地有机质含量较高, 土 壤微生物活动旺盛, 从而土壤呼吸速率加强, 因此野 外所测的橡胶林土壤呼吸速率高于季节雨林土壤呼 吸速率。很多研究表明, 土壤释放的 $\mathrm{CO}_{2}$ 量实际上 与土壤微生物的数量、生物量及活跃程度有关 (Jenkinson et al ., 1991)

3.2 土壤呼吸速率与温度的关系

根据实际观测资料, 用回归方法进行统计分析, 结果表明林地土壤呼吸速率与气温和地下 $5 \mathrm{~cm}$ 土 壤温度之间, 均具有显著的指数函数关系, 相关性达 到了 $1 \%$ 的显著水平。

季节雨林土壤呼吸速率与土壤温度的关系: $R$ $=1.5245 \mathrm{e}^{0.0771 T} \quad r^{2}=0.87$

土壤呼吸速率与气温的关系: $R=$ $2.0019 \mathrm{e}^{0.0647 T} \quad r^{2}=0.80$

橡胶林土壤呼吸速率与土壤温度的关系: $R=$ $1.4649 \mathrm{e}^{0.0781 T} \quad r^{2}=0.82$

土壤呼吸速率与气温的关系: $R=2.064 \mathrm{e}^{0.0599 T}$ $r^{2}=0.72$

其中, $R$ 为土壤呼吸速率 $\left(\mathrm{g} \cdot \mathrm{m}^{-2} \cdot \mathrm{d}^{-1}\right), T$ 为温 度 $\left({ }^{\circ} \mathrm{C}\right)$, 样本数 $n=150$ 。

从呼吸速率与温度的散点图 (图 2) 以及回归分 析都可以看出, 呼吸速率与土壤温度的相关性高于 和气温的相关性。这是因为, 在土壤表层的土壤生 物、微生物活动最旺盛, 对土壤呼吸速率的贡献较 大, 地下 $5 \mathrm{~cm}$ 的土壤温度能较准确地反映温度对土 壤微生物的影响, 而且根系主要集中在土壤 $0 \sim 20$ $\mathrm{cm}$ 以内 (单建平和陶大立, 1992), 根系呼吸也是土 壤呼吸中很重要的一部分。据刘建军研究秦岭天然 油松、锐齿栋林地土壤呼吸, 根的生物量与土壤呼吸 释放 $\mathrm{CO}_{2}$ 量呈现一次直线相关, 并且根系呼吸量与 气温、土壤温度均呈指数函数关系(刘建军等, 2003)。另外由于林地调落物层的覆盖, 土壤温度变 化缓慢, 而气温变化较剧烈, 透过林冠空隙的直射光 可使林地气温有一定的升高, 它可能对土壤温度影 响不大, 土壤温度比气温稳定一些, 土壤温度更能反 映温度对土壤呼吸速率的影响。

3.3 土壤呼吸速率与含水率的关系 

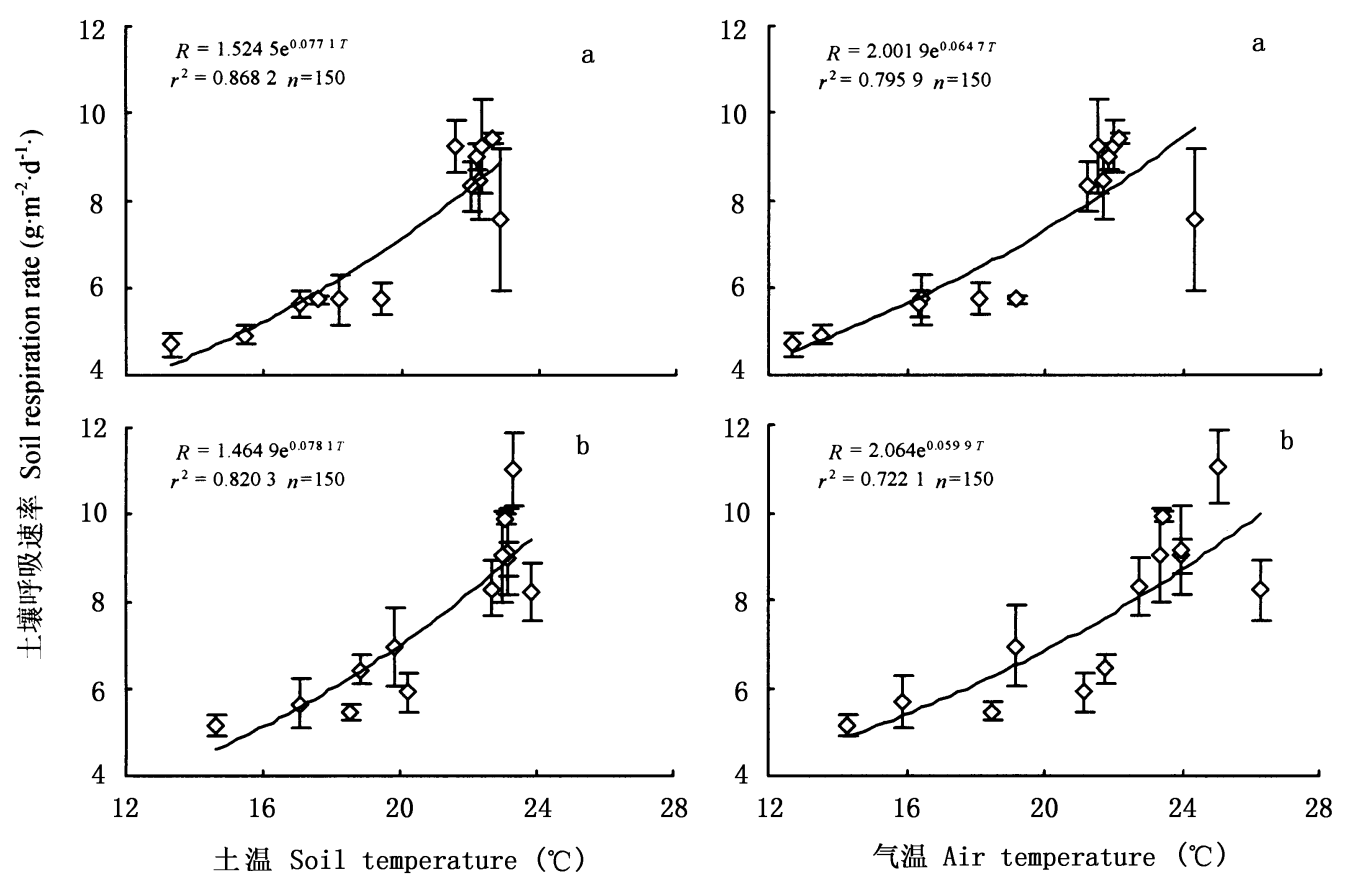

图 2 季节雨林 $(\mathrm{a})$ 、橡胶林 $(\mathrm{b})$ 土壤呼吸速率与土温、气温的关系

Fig.2 Relationship between the soil respiration rate of tropical seasonal rain forest (a) and rubber plantation (b) and soil temperature at $5 \mathrm{~cm} \mathrm{depth}$, air temperature

图中土壤呼吸数据为 12 个重复的平均值 \pm 标准误差 The data were the mean \pm standard error of 12 separate measurements

将土壤呼吸速率与土壤含水率进行回归分析, 结果表明两种林地土壤呼吸速率与土壤含水率之间 均具有显著线性关系, 相关性达到了 $1 \%$ 的显著水 平。

季节雨林: $R=0.255 W+0.4295 r^{2}=0.73$ $n=52$

橡胶林: $R=0.3347 W-1.7905 \quad r^{2}=0.63$ $n=52$

其中, $W$ 为土壤含水率 $(\%)$ 。

很多研究者证实, 在土壤含水率充足、不成为限 制因子的情况下, 土壤呼吸与土壤温度呈正相关。 而在水分含量成为限制因子的干旱、半干旱地区, 水 分含量与土壤温度共同起作用 (Mathes \& Schriefer, 1985; Moore \& Knowles, 1989; 王沝等, 2003)。本地 区为热带季风气候区, 雨水充足, 土壤含水率应该不 是土壤呼吸的主要限制因子, 但是在干季, 降水量比 较小, 天气比较干燥, 土壤含水率也比较低, 土壤呼 吸速率受土壤含水率和土壤温度的共同作用。

3.4 季节雨林、橡胶林地年土壤呼吸量

根据公式图 2 中 al 和 $\mathrm{bl}$ 的指数方程, 可计算 得出西双版纳季节雨林和橡胶林年土壤呼吸量:

$$
R_{a}=\sum_{i=1}^{z} r_{a i}
$$

式中: $R_{a}$ 为年土壤呼吸量, $r_{a}$ 为日土壤呼吸量, $z$ 为 一年的天数, 范围 $1 \sim 365$ 。

将 2003 年 9 月至 2004 年 8 月每天土壤温度实 测值代入上面公式, 可得到有关土壤呼吸 $\mathrm{CO}_{2}$ 年排 放量。季节雨林为 $2.64 \mathrm{~kg} \mathrm{CO} \cdot \mathrm{m}^{-2} \cdot \mathrm{a}^{-1}$, 橡胶林为 $2.80 \mathrm{~kg} \mathrm{CO} \cdot \mathrm{m}^{-2} \cdot \mathrm{a}^{-1}$ 。该研究中季节雨林土壤呼吸 量低于沙丽清等用静态箱-气相色谱法获得的土壤 呼吸量 $3.48 \mathrm{~kg} \mathrm{CO} \cdot \mathrm{m}^{-2} \cdot \mathrm{a}^{-1}$ (沙丽清等, 2004), 与 海南岛尖峰岭热带山地雨林土壤呼吸量 $2.99 \mathrm{~kg}$ $\mathrm{CO}_{2} \cdot \mathrm{m}^{-2} \cdot \mathrm{a}^{-1}$ (吴仲民等, 1997) 比较接近, 但是远远 低于泰国季雨林的土壤呼吸量 $9.39 \mathrm{~kg} \mathrm{CO} \cdot \mathrm{m}^{-2}$ • $\mathrm{a}^{-1}$ (Hashimoto et al.，2004), 只相当于其 $1 / 3$ 。 Davidson 等 (2000) 在亚马逊的研究也得到类似在泰 国的结果。这可能是水热条件的差异, 另外与森林 的生物量、生产力及土壤有机质、研究方法等因素有 关。

\section{5 季节雨林和橡胶林土壤呼吸的 $Q_{10}$}

对于土壤呼吸与温度的关系一般用 $Q_{10}$ 表示, 在生理生态学中 $Q_{10}$ 指温度在 $5 \sim 20{ }^{\circ} \mathrm{C}$ 时, 温度每增 加 $10{ }^{\circ} \mathrm{C}$, 呼吸速率增加的倍数。研究表明高纬度地 区的 $Q_{10}$ 大于低纬度地区的 $Q_{10}$ (方精云和魏梦华, 1998; 方精云等, 2001), 用 $Q_{10}$ 来计算全球温度上升 


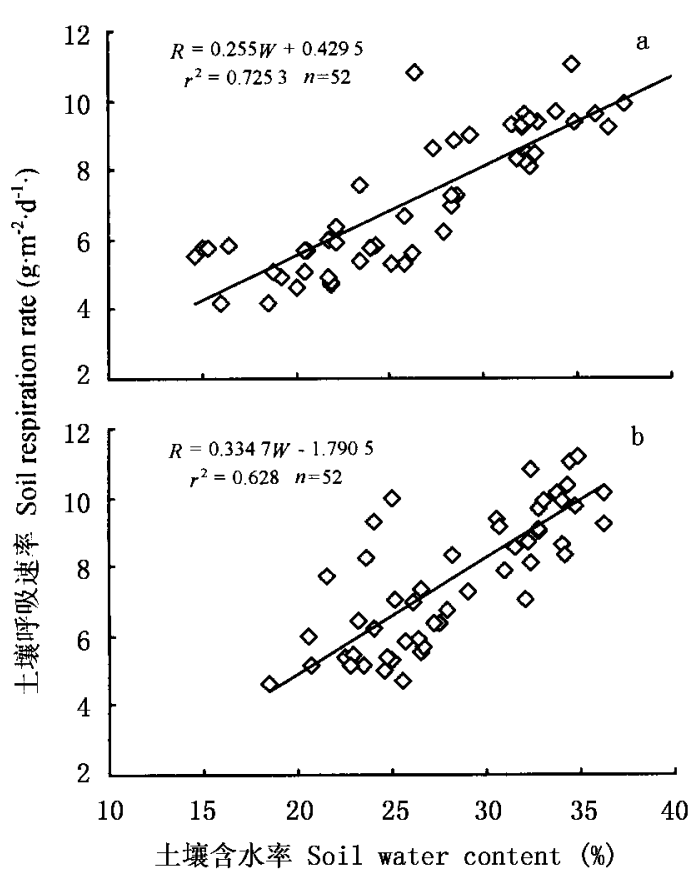

图 3 季节雨林 $(a)$ 、橡胶林 $(\mathrm{b})$ 土壤呼吸速率与 土壤含水率的关系

Fig. 3 Relationship between the soil respiration rate of tropical seasonal rainforest (a) and rubber plantation ( $b$ ) and soil water content

时土壤碳排放的趋势, 对了解全球变化下的碳循环 具有重要意义。

$$
Q_{10}=y(x+10) / y(x) \text {, 根据温度和土壤呼吸速 }
$$
率的指数相关关系, 季节雨林的 $Q_{10}$ 为 2.16 , 橡胶林 的 $Q_{10}$ 为 2.18 。该研究得到的 $Q_{10}$ 低于长白山地区 3 种森林类型土壤呼吸速率研究获得的 $Q_{10}$ 值 (王氷 等, 2003), 高于北京山区辽东栋林的 $Q_{10}$ 值(蒋高明 和黄银晓, 1997), 而与中亚热带东部森林获得的 $Q_{10}$ 值(黄承才等, 1999) 和 Singh 等 (Gupta \& Singh, 1981 )对草原土壤呼吸速率研究获得的 $Q_{10}$ 值相差不 大, 比文献报道的热带土壤呼吸的 $Q_{10}$ 稍微偏高(杨 昕和王明星, 2001), 沙丽清等用静态箱-气相色谱法 研究获得的西双版纳季节雨林的 $Q_{10}$ 值为 2.03 ( 沙 丽清等, 2004), 比该研究用碱吸收法获得的结果稍 微偏低。这是因为 $Q_{10}$ 除受温度、水分的影响外, 还 受植被类型、物候等的影响, 随季节而变化 (Boone et $a l ., 1998)$,气候年际间的变异大, 土壤呼吸年际间 变异也是比较大, 得到的 $Q_{10}$ 也不同, 另外观测方法 不同也可能导致比较大的差异。

\section{参 考 文 献}

Boone RD, Nadelhoffer KJ, Canary JD, Kaye JP (1998). Roots exert a strong influence on the sensitivity of soil respiration. $\mathrm{Na}$ - ture, $396,570-572$.

Davidson EA, Verchot LV, Cattanio JH, Ackerman IL, Carvalho JM (2000) . Effects of soil water content on soil respiration in forests and cattle pastures of eastern Amazonia. Biogeochemistry, (1), $53-69$.

Fang JY (方精云), Wei MH (魏梦华) (1998). Carbon cycle in the arctic terrestrial ecosystems in relation to the global warming. Acta Scientiae Circumstantiae (环境科学学报), 18,113-121. (in Chinese with English abstract)

Fang JY (方精云), Piao SL (朴世龙), Zhao SQ (赵淑清) (2001). The carbon sink: the role of the middle and high latitudes terrestrial ecosystems in the northern hemisphere. Acta Phytoecologica Sinica (植物生态学报), 25, 594 - 602.（in Chinese with English abstract)

Gupta SR, Singh JS (1981). Soil respiration in tropital grassland. Soil Biology and Biochemistry, 13,261 - 268.

Hashimoto S, Tanaka N, Suzuki M, Inoue A, Takizawa H, Kosaka I, Tanaka K, Tantasirin C, Tangtham N (2004). Soil respiration and soil $\mathrm{CO}_{2}$ concentration in a tropical forest, Thailand. Journal of Forest Research, 9,75-79.

Huang CC (黄承才), Ge Y (葛漟), Chang J (常杰), Lu R (卢 蓉), Xu QS (徐青山) (1999). Studies on the soil respiration of three woody plant communities in the east mid-subtropical zone, China. Acta Ecologica Sinica (生态学报), 19, 324 328. (in Chinese with English abstract)

Jenkinson DS, Adams DE, Wild A (1991). Model estimates of $\mathrm{CO}_{2}$ emissions from soil in response to global warming. Nature, $35,304-306$.

Jiang AL (江爱良) (1987). Ecological climate and botany plants of Xishuangbanna, Yunnan. Natural Resource (自然资源), (2) , $32-37,15$. (in Chinese)

Jiang GM (蒋高明), Huang YX (黄银晓) (1997). A study on the measurement of $\mathrm{CO}_{2}$ emission from the soil of the simulated Quercus liaotungensis forest sampled from Beijing mountain areas. Acta Ecologica Sinica (生态学报), 17,477 - 482. (in Chinese with English abstract)

Krischbaum N (1995). The temperature of soil organic matter decomposition and the effect of global warming on soil organic storage. Soil Biology and Biochemistry, 27,735-760.

Kucera C, Kirlcham D (1971). Soil respiration studies in tallgrass prairie in Missouri. Ecology, 52, 912-915.

Liu JJ (刘建军), Wang DX (王得祥), Lei RD (雷瑞德), Wu QX (吴钦孝) (2003). Soil respiration and release of carbon dioxide from nature forest of Finus tabulaeformis and Quercus aliena var. acuteserrata in Qinling Mountains. Scientia Silvae Sinicae (林业科学), 39 (2),8-13. (in Chinese with English abstract)

Liu SH (刘绍辉), Fang JY (方精云) (1997). Effect factors of soil respiration and the temperature's effects on soil respiration in the global scale. Acta Ecologica Sinica (生态学报), 17, 469 - 476. (in Chinese with English abstract) 
Liu SH (刘绍辉), Fang JY (方精云), Makoto K (清田信) (1998). Soil respiration mountainous temperature forests in Beijing, China. Acta Phytoecologica Sinica (植物生态学报), 22, 119 - 126. (in Chinese with English abstract)

Mathes K, Schriefer T (1985). Soil respiration during secondary succession influences of temperature and moisture. Soil Biology and Biochemistry, 17, $205-211$.

Moore TR, Dalva M (1993). The influence of temperature and water table position on carbon dioxide and methane emissions from laboratory columns of peat land soils. Journal of Soil Science, $44,651-664$.

Moore TR, Knowles R (1989). The influence of water table levels on methane and carbon dioxide emissions from peat land soils. Canadian Journal of Soil Science, 69, 33 - 38 .

Ren YH (任泳红), Cao M (曹敏), Tang JW (唐建维), Tang Y (唐勇), Zhang JH (张建侯) (1999). A comparative study on litterfall dynamics in a seasonal rain forest and a rubber plantation in Xishuangbanna, SW China. Acta Phytoecologica Sinica (植物 生态学报), 23,418-425. (in Chinese with English abstract) Sha LQ (沙丽清), Zheng Z (郑征), Tang JW (唐建维), Wang YH (王迎红), Zhang YP (张一平), Cao M (曹敏), Wang R (王锐), Liu GR (刘广仁), Wang YS (王跃思), Sun Y (孙 扬) (2004). Soil respiration of tropical seasonal rainforest in Xishuangbanna, SW China. Science in China Ser. D Earth Sciences (中国科学 D 辑・地球科学), 34 (Suppl. II ), 167 174. (in Chinese)

Shan JP (单建平), Tao DL (陶大立) (1992). Overseas researches on tree fine root. Chinese Journal of Ecology (生态学 杂志), 11(4),46-49. (in Chinese with English abstract)

Statistical Bureau of Yunnan Province（云南省统计局）（1998）.
Yunnan Statistical Yearbook (云南统计年鉴). China Statistics Press, Beijing, 39-61. (in Chinese)

Wang M (王炎沝), Ji LZ (姬兰柱), Li QR (李秋荣), Liu YQ (刘延秋) (2003). Effect of temperature and moisture on soil respiration in different forest types in Changbai Mountain. Chinese Journal of Applied Ecology (应用生态学报)，14,1234 1238. (in Chinese with English abstract)

Wildung RE, Garland TR, Buschbom RL (1975). The interdependent effects of soil temperature and water content on soil respiration rate and plant root decomposition in arid grassland soils. Soil Biology and Biochemistry, 7, 373-378.

Wu ZM (吴仲民), Zeng QB (曾庆波)，Li YD (李意德), Zhou GY (周广益), Du ZH (杜志鹄), Lin MX (林明献) (1997). A preliminary research on the carbon storing and $\mathrm{CO}_{2}$ release of the tropical forest soils in jianfenling, Hainan Island, China. Acta Phytoecologica Sinica (植物生态学报), 21,416-423. (in Chinese with English abstract)

Yang JC (杨靖春), Ni P (倪平), Zu YG (祖元刚), Zhu TC (祝廷成), Wang DZ (王大珍) (1989). The seasonal variation of respiration rate of soil microorganisms related to soil temperature and soil moisture on the Leymus chinensis grassland in Northeast China. Acta Ecologica Sinica (生态学报), 9, 139 - 142. (in Chinese with English abstract)

Yang X (杨昕)，Wang MX (王明星) (2001). Reviews of several aspects of terrestrial carbon cycling. Advance in Earth Sciences (地球科学进展), 16,427-435. (in Chinese with English abstract)

Zhu H (朱华) (1999). The tropical rain forest vegetation in Xishuangbanna. Tropical Geography (热带地理), 10, 233 240. (in Chinese with English abstract) 